9. World Health Organization. Screening, assessment and management of neonates and infants with complications associated with Zika virus exposure in utero. 2016 Aug 30 [cited 2018 Jan 30]. http://apps.who.int/iris/bitstream/10665/204475/1/WHO_ ZIKV_MOC_16.3_eng.pdf?ua $=1$

10. Betunde AG. Casos de microcefalia en Guinea Bissau, 2015-2016. 2016 [cited 2018 Jan 30]. http://vigisalud.gov.py/muestras/
VIImuestra/Presentaciones_orales/dia1_LUNES_12-12-2016/ PO_tarde_12_12_16/PO11.pdf

Address for correspondence: Maiken Worsøe Rosenstierne, Statens Serum Institut, Department of Microbiological Diagnostics and Virology, Artillerivej 5 Copenhagen S 2300, Denmark; email: mwr@ssi.dk

\section{Heterogeneous and Dynamic Prevalence of Asymptomatic Influenza Virus Infections}

\author{
Nancy H.L. Leung, Benjamin J. Cowling \\ Author affiliation: The University of Hong Kong, Hong Kong, China \\ DOI: https://doi.org/10.3201/eid2405.160782
}

To the Editor: We read with interest the article by Furuya-Kanamori et al. on the proportion of influenza virus infections that are asymptomatic or subclinical (1), and we are troubled by a series of fundamental flaws and errors. We were concerned that the authors presented pooled estimates of the asymptomatic fraction, given the massive heterogeneity in estimates ( $\mathrm{I}^{2}$ values of $97 \%-98 \%$ in Table $1)$. It is not considered good practice to present pooled estimates in instances of massive heterogeneity (2). We were very surprised that the authors included volunteer challenge studies because it is well known that the severity of these infections can be modulated by the route of administration and possibly the infectious dose. We also were surprised that human infections with avian influenza viruses were included because the epidemiology of these infections differs markedly from that of human influenza viruses. These studies were mistakenly labeled as studies of pandemic influenza in online Technical Appendix 1 Table 1 (https://wwwnc. cdc.gov/EID/article/22/6/15-1080-Techapp1.pdf). When reviewing serologic studies, the authors did not define a specific antibody titer threshold but relied on the choices made in individual studies; studies that inferred influenza virus infections based on low postepidemic hemagglutination-inhibition titers, such as 10 or 20 , may lack specificity because some persons could have preexisting antibodies (3). Measurement error can also be a concern. The authors probably should have excluded such studies.

In another systematic review of the asymptomatic fraction of influenza virus infections (4), we found that study designs could explain a great deal of heterogeneity in the asymptomatic fraction in studies such as outbreak investigations that used molecular testing to confirm influenza virus infections rather than serologic studies that used antibody titer measurements to indicate infections. Asymptomatic fractions were higher in general, and much more heterogeneous, in studies that followed the latter approach.

The authors received financial support from the Harvard Center for Communicable Disease Dynamics from the National Institute of General Medical Sciences (grant no. U54 GM088558), the Area of Excellence Scheme of the University Grants Committee of Hong Kong (grant no. AoE/M-12/06), and a commissioned grant from the Health and Medical Research Fund from the Government of the Hong Kong Special Administrative Region.

\section{References}

1. Furuya-Kanamori L, Cox M, Milinovich GJ, Magalhaes RJ, Mackay IM, Yakob L. Heterogeneous and dynamic prevalence of asymptomatic influenza virus infections. Emerg Infect Dis. 2016;22:1052-6. http://dx.doi.org/10.3201/eid2206.151080

2. Greenland S, O’Rourke K. Meta-analysis. In: Rothman KJ, Greenland S, Lash TL, editors. Modern epidemiology. 3rd ed. Philadelphia: Wolters Kluwer Health/Lippincott Williams \& Wilkins; 2008. p. 652.

3. Broberg E, Nicoll A, Amato-Gauci A. Seroprevalence to influenza A(H1N1) 2009 virus - where are we? Clin Vaccine Immunol. 2011;18:1205-12. http://dx.doi.org/10.1128/CVI.05072-11

4. Leung NH, Xu C, Ip DK, Cowling BJ. The fraction of influenza virus infections that are asymptomatic: a systematic review and meta-analysis. Epidemiology. 2015;26:862-72. http://dx.doi.org/10.1097/EDE.0000000000000340

Address for correspondence: Benjamin J. Cowling, WHO Collaborating Centre for Infectious Disease Epidemiology and Control, School of Public Health, The University of Hong Kong, 21 Sassoon Rd, Pokfulam, Hong Kong; email: bcowling@hku.hk

\section{Luis Furuya-Kanamori, Laith Yakob}

Author affiliations: Qatar University, Doha, Qatar

(L. Furuya-Kanamori); Australian National University, Canberra, Australian Capital Territory, Australia (L. Furuya-Kanamori); London School of Hygiene \& Tropical Medicine, London, UK (L. Yakob)

DOI: https://doi.org/10.3201/eid2405.180075 
In Response: We thank Leung and Cowling (1) for taking time to comment on our article (2). One problem with the random effects model is the rapid decline in performance of the model as the heterogeneity within studies increases. Extensive heterogeneity for asymptomatic $\left(\mathrm{I}^{2}=97 \% ; \mathrm{T}^{2}=0.31\right)$ and subclinical $\left(\mathrm{I}^{2}=97 \% ; \mathrm{T}^{2}=0.45\right)$ infection was identified. However, the model selected to pool the prevalence estimates-inverse variance heterogeneity-maintains its coverage at the nominal level, even when large heterogeneity is present (3).

Regarding inclusion criteria, we elected to review all publications detailing asymptomatic influenza prevalence in humans, as is made clear from the original article's title onward. This method included experimental studies, as well as newly emerging zoonotic strains. We note further that the 2 experimental studies in our review had subclinical influenza infection levels within the range identified in the pooled estimate of the metaanalysis $(43.4 \%, 95 \%$ CI $25.4 \%-61.8 \%)$. Also, because antibody titers can vary drastically with technique used and between laboratories, we used the antibody titer threshold defined by each individual study.

The results/conclusions from the study published by Leung et al. (4) cannot be compared with those reported in our meta-analysis (2) for 2 important reasons. First, the case definition for asymptomatic was different; Leung et al. grouped patients without signs and symptoms (asymptomatic in our metaanalysis) with patients that did not fulfill the criteria of influenza-like illness (subclinical in our meta-analysis). We explained in our article why pooling asymptomatic and subclinical cases is inappropriate and likely to provide spurious results. As an example of how the case definition can affect the results, Pascalis et al. found that in the same group of patients, $30.6 \%$ had subclinical infection (not fulfilling criteria for influenza-like illness) but only $1.6 \%$ had no symptoms at all (5). Second, the number of studies included in the 2 meta-analyses was different: our comprehensive review comprised 55 studies, whereas Leung et al. included a subset of only 30 studies pertaining specifically to seasonal influenza. The different studies included and different meta-analytical methods unsurprisingly yielded different outcomes.

\section{References}

1. Leung NHL, Cowling BJ. Heterogeneous and dynamic prevalence of asymptomatic influenza virus infections. Emerg Infect Dis. 2018 May [cited 2018 Mar 5]. https://doi.org/10.3201/eid2405.160782.

2. Furuya-Kanamori L, Cox M, Milinovich GJ, Magalhaes RJ, Mackay IM, Yakob L. Heterogeneous and dynamic prevalence of asymptomatic influenza virus infections. Emerg Infect Dis. 2016;22:1052-6. http://dx.doi.org/10.3201/eid2206.151080

3. Doi SA, Barendregt JJ, Khan S, Thalib L, Williams GM. Simulation comparison of the quality effects and random effects methods of meta-analysis. Epidemiology. 2015;26:e42-4. http://dx.doi.org/10.1097/EDE.0000000000000289
4. Leung NHL, Xu C, Ip DKM, Cowling BJ. Review article: the fraction of influenza virus infections that are asymptomatic: a systematic review and meta-analysis. Epidemiology. 2015;26:86272. http://dx.doi.org/10.1097/EDE.0000000000000340

5. Pascalis H, Temmam S, Turpin M, Rollot O, Flahault A, Carrat F, et al. Intense co-circulation of non-influenza respiratory viruses during the first wave of pandemic influenza $\mathrm{pH} 1 \mathrm{N1} / 2009$ : a cohort study in Reunion Island. PLoS One. 2012;7:e44755. http://dx.doi.org/10.1371/journal.pone.0044755

Address for correspondence: Luis Furuya-Kanamori, Qatar University, Department of Population Medicine, College of Medicine, 2713 Al Hala St, Doha, Qatar; email: luisfuruya@qu.edu.qa

\section{Mycobacterium lepromatosis Lepromatous Leprosy in US Citizen Who Traveled to Disease-Endemic Areas}

\author{
Ajay Vir Singh, Devendra Singh Chauhan
}

Author affiliation: ICMR-National JALMA Institute for Leprosy and Other Mycobacterial Diseases, Agra, India

\section{DOI: https://doi.org/10.3201/eid2405.171972}

To the Editor: The article by Virk et al. (1) highlighted that a person can acquire Mycobacterium lepromatosis infection without exposure to a person infected with leprosy or to known vectors during short stays ( 2 trips of 7 days each over 3 calendar years) in Mexico. The authors then concluded that $M$. lepromatosis lepromatous leprosy is a travel-related hazard for travelers to Mexico or other disease-endemic areas. We note that the exact source of acquiring the M. lepromatosis infection by the patient in this study was entirely uncertain, and experimental evidence was not enough to prove $M$. lepromatosis to be a travel-related hazard.

In contrast, Jessamine et al. (2) reported M. lepromatosis infection and leprosy-like illness in a patient in Canada who had no history of contact or travel to leprosy-endemic areas. Jessamine et al. indicated that transmission dynamics of $M$. lepromatosis infection is complex, and undiscovered mechanisms or unknown reservoir interactions may exist in such areas of nonendemic regions. Previous studies have also reported the roles of subclinical cases and environmental reservoirs in the transmission of leprosy $(3,4)$. However, Virk et al. have not disentangled other possible sources (existence of unrecognized subclinical cases, contact with 